Document downloaded from:

http://hdl.handle.net/10251/52828

This paper must be cited as:

Guardiola, C.; Pla Moreno, B.; Blanco-Rodriguez, D.; Mazer, A.; Hayat, O. (2013). A bias correction method for fast fuel-to-air ratio estimation in diesel engines. Proceedings of the Institution of Mechanical Engineers, Part D: Journal of Automobile Engineering. 227(8):1099-1111. doi:10.1177/0954407012473415.

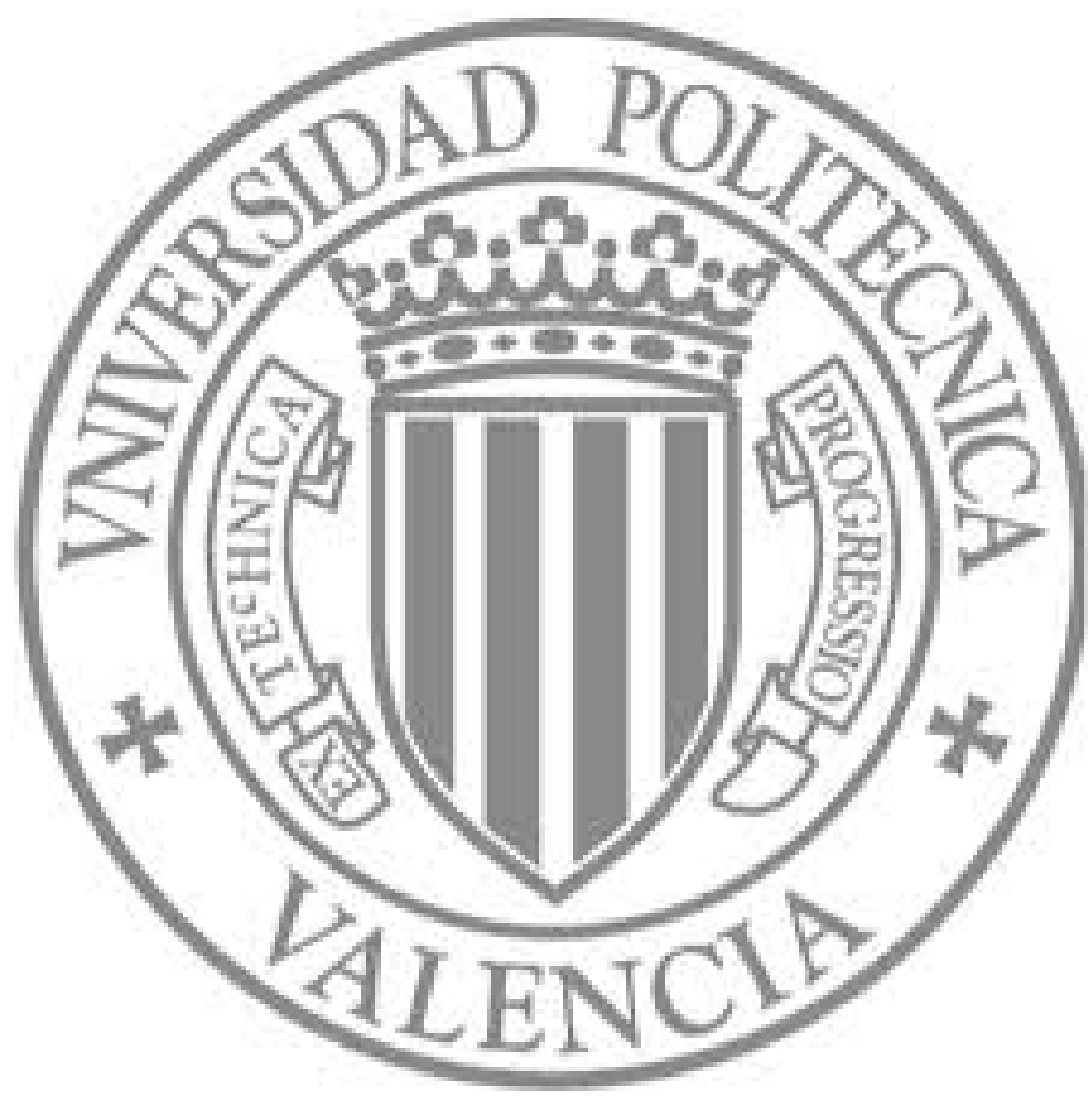

The final publication is available at

http://dx.doi.org/10.1177/0954407012473415

Copyright SAGE Publications (UK and US) 


\title{
A bias correction method for fast fuel-to-air estimation in diesel engines
}

\author{
C. Guardiola, B. Pla, D. Blanco-Rodriguez
}

CMT Motores Térmicos, Universitat Politècnica de València, Camino de Vera s/n, E-46022 Valencia, Spain

A. Mazer, O. Hayat

Diesel Engine Control Department, PSA Peugeot Citroën, 18 rue des Fauvelles, 92256 La Garenne Colombes, France

\begin{abstract}
$\lambda$ probes in turbocharged diesel engines are usually located downstream the turbine, exhibiting a good dynamic response but a significant delay because of exhaust line transport and hardware itself. With the introduction of after-treatment systems, new sensors that can measure exhaust concentrations are required for an optimal control and diagnosis. Zirconia-based potentiometric $\left(\mathrm{ZrO}_{2}\right)$ sensors permit measuring $\mathrm{NO}_{\mathrm{x}}$ and oxygen with the same hardware. However, their dynamic response is slower and more filtered than traditional $\lambda$ probes, and in addition, sensor location downstream after-treatment systems even increases this problem. The paper uses the Kalman filter for the online dynamic estimation of the relative fuel-to-air ratio $\lambda^{-1}$ in a turbocharged diesel engine. The combination of a fast drifted fuel-to-air ratio model with an slow but accurate $\mathrm{ZrO}_{2}$ sensor permits correcting model bias. This bias is modelled with a look-up table depending on the engine operating point and integrated online on the basis of the Kalman filter output. Calculation burden is alleviated by using the converged gain of the steady-state Kalman filter, precalculated offline. Finally, robustness conditions for stopping the bias updating are included for accounting with sensor and model uncertainties. The proposed algorithm and sensor layout are successfully proved in a turbocharged diesel engine. Experimental and simulation results are included to support the algorithm validation.
\end{abstract}

Keywords: Kalman filter; bias correction; drift correction; look-up table; turbocharged engine; fuel-to-air; richness; adaptive modelling

\section{Introduction}

Three decades ago, the introduction of narrow-band or exhaust gas oxygen (EGO) sensors [1] was the key for the implantation of the three-way catalysts. Afterwards, universal exhaust gas oxygen (UEGO) or wide-band $\lambda$ sensors were implemented in diesel engines. $\lambda$ measurement in diesel is used for bounding fuel injection and for correcting injector drift. In the case of

Email addresses: carguaga@mot.upv . es (C. Guardiola), benplamo@mot.upv .es (B. Pla), dablarod@mot . upv. es (D. Blanco-Rodriguez), alexandre.mazer@mpsa.com (A. Mazer), olivier.hayat@mpsa.com (O. Hayat)

Preprint submitted to Proceedings of the Institution of Mechanical Engineers, Part D: Journal of Automobile EngineeringDecember 12, 2012 
low temperature combustion processes [2], intake charge composition, and hence $\lambda$, has a key influence in the combustion stability and control [3, 4]. In the last 15 years, zirconia-based potentiometric $\left(\mathrm{ZrO}_{2}\right) \mathrm{NO}_{\mathrm{x}}$ sensors $[5,6,7]$ have suffered a big development due to the special attention paid to nitrogen oxides $\left(\mathrm{NO}_{\mathrm{x}}\right)$ emissions in turbocharged diesel engines (see [8]). These sensors can measure $\mathrm{NO}_{\mathrm{x}}$ concentration and $\lambda$ in the exhaust.

Implantation conditions of exhaust concentration sensors significantly depend on the aftertreatment configuration. A wide variety of solutions can be implemented downstream the turbine in turbocharged diesel engines, such as the selective catalyst reduction (SCR) and deNO$_{x}$ catalyst for $\mathrm{NO}_{\mathrm{x}}$ reduction, diesel particulate filter (DPF) for soot and PM reduction, and diesel oxidation catalyst (DOC) for $\mathrm{HC}$ and $\mathrm{CO}$ oxidation. Manufacturers are struggling for finding the configuration of systems and sensors that optimises the trade-off between low emissions, efficient torque production, low cost and robustness. Usual position of UEGO sensor for air-to-fuel ratio determination is directly downstream the turbine: this way the sensor is near of the source, but avoids the large range of pressure variation that exists in the exhaust manifold. However, if SCR or deNO $\mathrm{N}_{\mathrm{x}}$ catalysts are used, a $\mathrm{NO}_{\mathrm{x}}$ sensor is needed for their control. Such sensor must be placed downstream the after-treatment devices in order to measure tail-pipe emissions, as sketched in the options 1, 2 and 3 of Figure 1. Current $\mathrm{NO}_{\mathrm{x}}$ sensors are based on planar $\mathrm{ZrO}_{2}$ technology, and fit two ion current pumps, the first of them providing a measurement of the oxygen concentration in the gas (a well explanation on this is in [6]). Hence, it seems possible to avoid the UEGO sensor and just rely on the $\mathrm{NO}_{\mathrm{x}}$ sensor information, as depicted in the third exhaust line of Figure 1.

However, because $\mathrm{NO}_{\mathrm{x}}$ sensor is located far from the engine, sensor performance must be examined, since sensor responses are not always enough for control or real-time purposes. UEGO sensors exhibit fast responses time around $70 \mathrm{~ms}$ with a sufficient accuracy [9]; this can be improved, as proposed in [10], moving the $\mathrm{O}_{2}$ sensor upstream the turbine and using a Kalman filter (KF) [11] for coping with pressure effect on the output signal. $\mathrm{NO}_{\mathrm{x}}$ sensor response time is about $500 \mathrm{~ms}$, but if placed downstream the after-treatment systems, its response is affected by a considerable transport delay and filtering. Figure 2 compares $\lambda^{-1}$ signals for a UEGO sensor located upstream after-treatment system, and for $\mathrm{a} \mathrm{NO}_{\mathrm{x}}$ sensor located downstream the after-treatment system in a turbocharged diesel engine. $\mathrm{NO}_{\mathrm{x}}$ signal is significantly slower and more filtered than UEGO sensor one, although the steady-state accuracy seems to be sufficiently accurate at a glance.

Sensor response can be evaluated when a step variation in the injected fuel mass is applied, as shown in Figure 3, where a sharp variation from 30 to $15 \mathrm{mg} / \mathrm{str}$ of injection has been done. Signal from $\mathrm{NO}_{\mathrm{x}}$ sensor $\lambda_{s}^{-1}$ is compared with the expected variation in $\lambda^{-1}$. Because of the location and sensor characteristics, sensor is not able to reproduce the step.

Models and virtual sensoring techniques [12, 13, 14, 15] may be used as an alternative to sensors, since present fast dynamic responses and offline prediction capabilities. However, models suffer from bias that varies with time and operating conditions. The inability of standard models to cope with engine drift is one of the main problems that modelling researchers must challenge. Back to Figure 3, a model signal $\lambda_{m}^{-1}$, based on the injected fuel mass $m_{f}$ estimated by the electronic control unit (ECU) and the air mass flow $m_{a}$ determined from a hot wire anemometer, has been also represented. Comparing to the sensor, model is faster and non-delayed but presents bias with respect to sensor steady-state value. Furthermore, this bias may vary before and after the step.

This paper presents a methodology for combining data from models and sensors applied to the oxygen estimation in the exhaust line of a turbocharged diesel engine. For that, $\mathrm{a} \mathrm{NO}_{\mathrm{x}}$ 


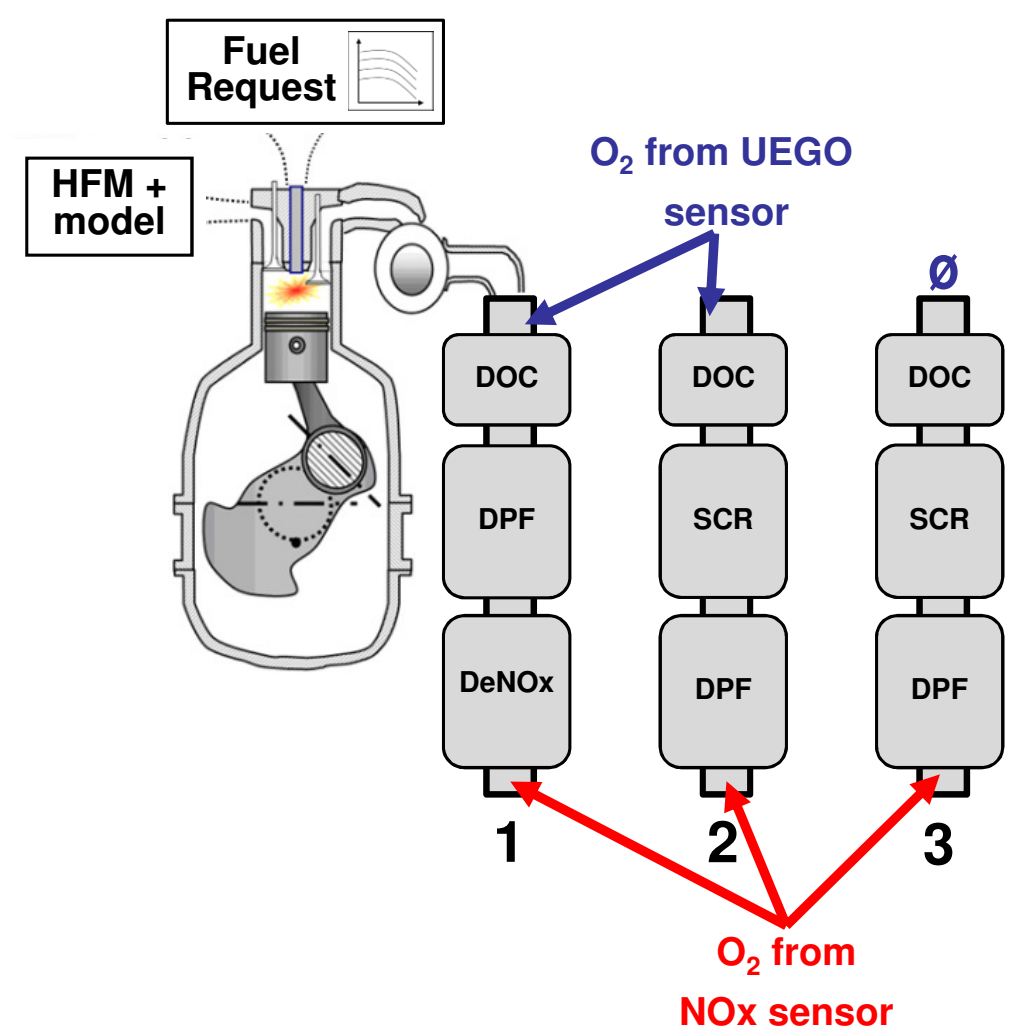

Figure 1: Oxygen sensors configuration setup for a turbocharged diesel engine.

sensor is located downstream the after-treatment systems and a fast simple model is calculated by using available signals of intake air mass flow and injected fuel quantity in a series turbocharged diesel engine with after-treatment systems. A look-up table, scheduled by injected fuel mass and engine speed, is added to the model for correcting the bias and a KF observer is used for tracking the bias evolution. Fuel-to-air ratio $\left(\lambda^{-1}\right)$ is estimated instead of $\lambda$ because it presents a bounded value (ranging from 0 to 1 , although slightly higher values can be reached during engine load transients). The algorithm does not require a special knowledge on after-treatment systems modelling as proposed model is considered as sufficiently fast for representing actual $\lambda^{-1}$ dynamics.

Paper is structured as follows. Section 2 describes the experimental set-up and the two main possibilities for inferring $\lambda$ in diesel engines, as sensors and models. Section 3 depicts the $\lambda$ estimation problem, proposing a drift correction algorithm using a Kalman filter and introducing some robustness condition for coping with signal uncertainties and the use of look-up tables for modelling drift dependence on engine operating point. Section 4 shows the experimental validation of the proposed algorithm in a turbocharged diesel engine. More concretely, results on fuel injection steps and New European Driving Cycle NEDC are shown. Finally, section 5 gives the conclusions. 


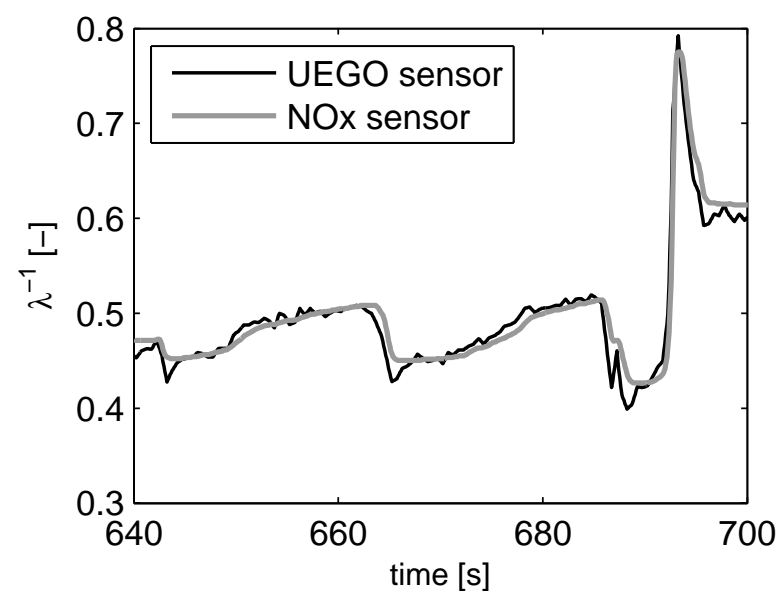

Figure 2: $\lambda^{-1}$ measurement from a UEGO sensor located downstream the turbine and from a $\mathrm{NO}_{\mathrm{x}}$ sensor downstream the after-treatment systems, with configuration number 2 of Figure 1.

\begin{tabular}{ll}
\hline Stroke $(S)$ & $96 \mathrm{~mm}$ \\
Bore $(D)$ & $85 \mathrm{~mm}$ \\
$S / D$ & 1.129 \\
Number of cylinders $(\mathrm{z})$ & 4 \\
Displacement & $2179 \mathrm{~cm}^{3}$ \\
Turbocharging system & Sequential parallel[16] \\
Valves by cylinder & 4 \\
Maximum power & $125 \mathrm{~kW} @ 4000 \mathrm{rpm}$ \\
Compression ratio & $17: 1$ \\
\hline
\end{tabular}

Table 1: Engine main characteristics.

\section{Experimental set-up and available information on $\lambda$}

\subsection{Experimental set-up}

Tests have been performed in a common rail diesel engine with the exhaust line 3 presented in Figure 1 and with the main characteristics shown in Table 1. The engine is installed on an engine test bench and coupled to a variable frequency eddy current dynamometer that allows carrying out dynamic tests. An open ECU permits varying injection parameters, such as injection pressure, start of injection (SOI) and injection duration. Boost pressure and exhaust gas recirculation (EGR) control set points can also be calibrated.

A real time hardware system is connected via CAN with a rapid prototyping system, capable of sending to and receiving from ECU channels, both via ETK connection. A commercial $\mathrm{NO}_{\mathrm{x}}$ $\mathrm{ZrO}_{2}$ sensor is used for measuring $\mathrm{O}_{2}$ concentration downstream the after-treatment systems (from which $\lambda^{-1}$ was derived). Additionally, a UEGO sensor is installed at the turbine outlet for comparison. For providing a reference signal, an exhaust gas analyser, whose measurement is based on the non-dispersive infrared method, is used. The air mass flow signal $m_{a}$ comes from 


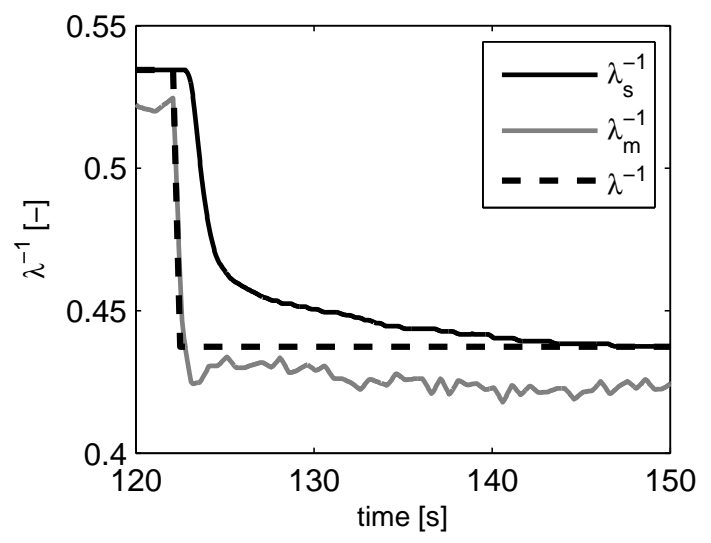

Figure 3: $\lambda_{s}^{-1}, \lambda_{m}^{-1}$ and expected actual $\lambda^{-1}$ signals during an injection step from $6 \mathrm{mg} / \mathrm{str}$ to $3 \mathrm{mg} / \mathrm{str}$ at $1500 \mathrm{rpm}$.

a hot wire sensor installed upstream the compressor, and fuel injected quantity $m_{f}$ is estimated by the ECU. A number of 354 steady-state tests are carried out for the static calibration, while a set of injection steps and homologation cycles are made for dynamic calibration and algorithm verification.

\subsection{Sensor measurement}

$\mathrm{NO}_{\mathrm{x}}$ sensor provides a very accurate information of $\lambda^{-1}$ in steady-state operation. Static measurements of sensor $\lambda_{s}^{-1}$ are compared to those of the gas analyser $\lambda_{g}^{-1}$ in Figure 4.

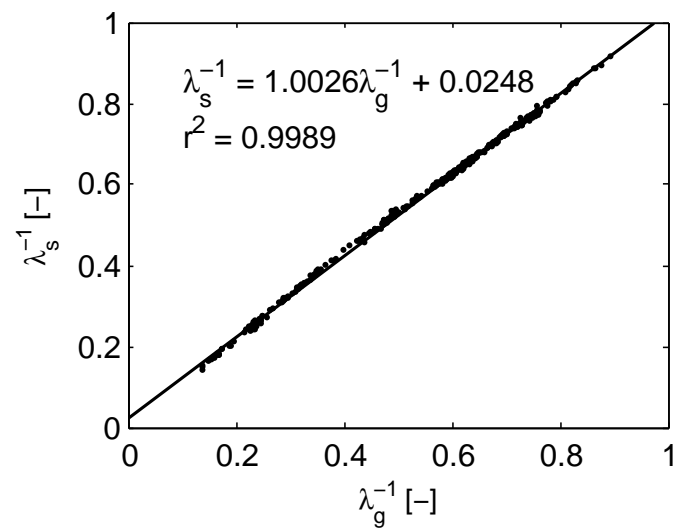

Figure 4: $\lambda_{s}^{-1}$ and $\lambda_{g}^{-1}$ for different steady operating conditions; linear fit and correlation coefficient are represented.

The slow sensor dynamic response, yet shown in Figure 3 for an injection step, is explained by several reasons: distance and gas volumes (after-treatment systems, turbine and manifolds) between engine exhaust and sensor location affect transport delay and distort the signal; the sensor measurement principle and sensor hardware itself; and the acquisition chain. Although slow, the sensor is quite precise, since several repetitions of the same test provide similar results. 
This is illustrated in Figure 5, where 2 repetitions of the same fuel step are depicted for 2 different engine speeds. Top plots show a step up (left) and step down (right) in injection for $1550 \mathrm{rpm}$ and bottom plots the same for $2250 \mathrm{rpm}$. Despite the sensor precision, it must be considered that the dynamic response is significantly affected by the operative conditions (e.g. sensor response in bottom plots in Figure 5 is always faster than in top plots).
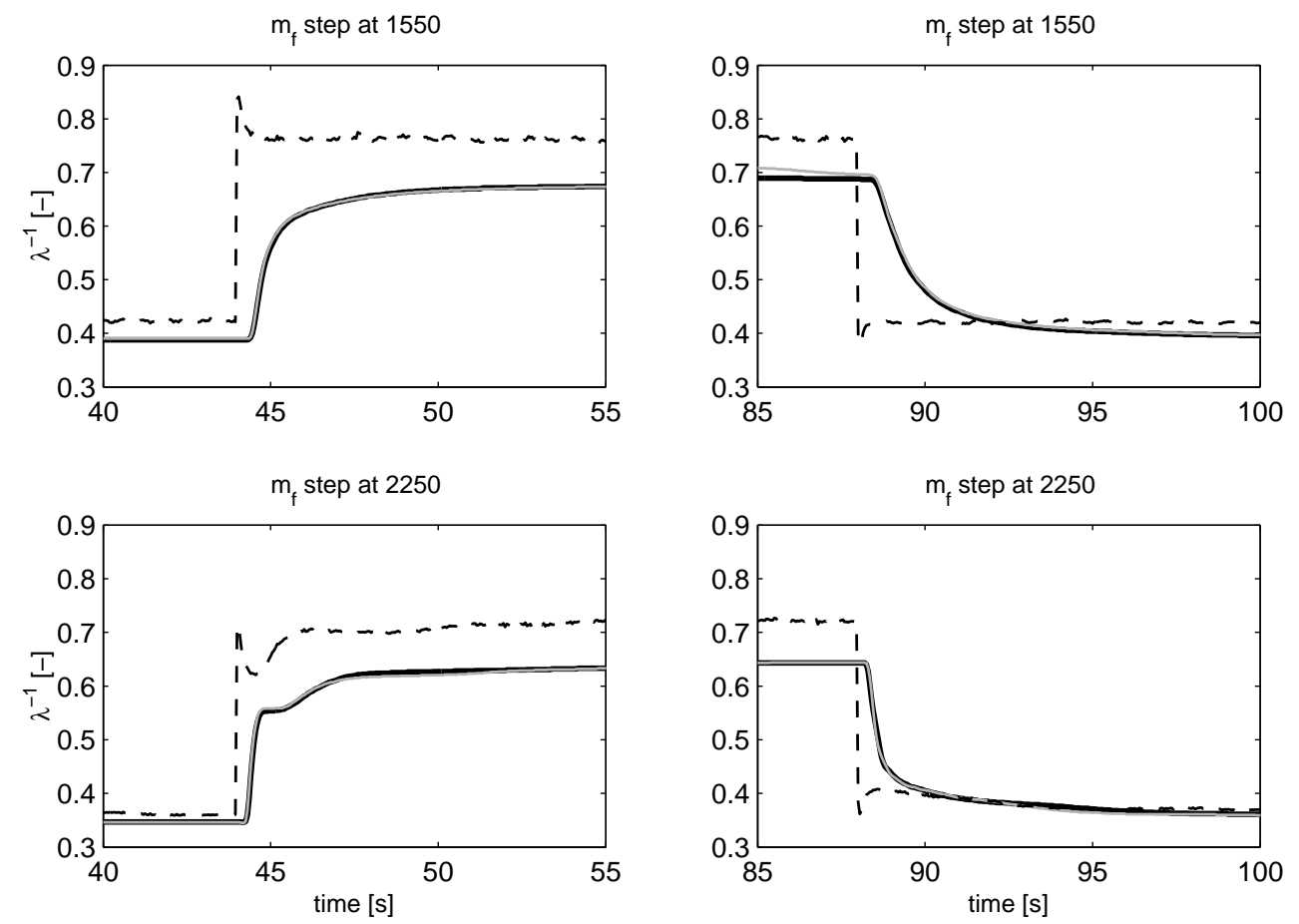

Figure 5: Two sensor responses (solid lines) for injection steps from $15 \mathrm{mg} / \mathrm{str}$ to $30 \mathrm{mg} / \mathrm{str}$ (left) and the opposite (right) at $1550 \mathrm{rpm}$ (top) and $2250 \mathrm{rpm}$ (bottom). $\lambda_{m}^{-1}$ is provided for comparison (dashed black).

According with the sensor steady-state accuracy, the measured value $\lambda_{s}^{-1}$ can be related with the actual value of $\lambda^{-1}$ by the application of a pure transport delay and a filter:

$$
\lambda_{s}^{-1}=\lambda_{f}^{-1}+v=\frac{1-a}{1-a z^{-1}} z^{-\tau / T} \lambda^{-1}+v
$$

where $z^{-1}$ represents the unit delay of the discrete representation and $T$ is the sampling period. Although other model structures could be used, a delayed linear first order discrete model is chosen, where the main important parameters are the filtering quantity $a$ and the sensor-to-model pure delay $\tau$. A noise $v$ has been added to the delayed and filtered value $\lambda_{f}^{-1}$ in order to represent the measurement noise and other uncontrolled effects.

A dynamic characterisation of the sensor is mandatory for identifying (1). Procedures based on provoking step transitions in gas concentration may be employed [17, 18], although these add complexity and cannot be easily carried out during normal engine operation. Another option, 
suitable for online purposes, is provoking step-like transitions in the measured variables by modifying fast actuators such as the injection profile, which are electronically driven parameters and thus no more than a cycle delay is expected [19]. Then, $\lambda^{-1}$ sharp variations can be easily made in current engines during their normal operation by causing injection steps, and a least-square fitting may be used for fitting (1) (although robust recursive identification techniques could also be used [20]).

Figure 6 shows the evolution of the measured $\lambda_{s}^{-1}$ and the identified sensor model $\lambda_{f}^{-1}$ for two different operating conditions. Top plot is used for identification while validation is provided by the lower plot. The fitting is good, even in the bottom plot, although a slight error can be appreciated, which suggests that the dependence of the sensor dynamics with the engine operating point may be neglected in a first approach.
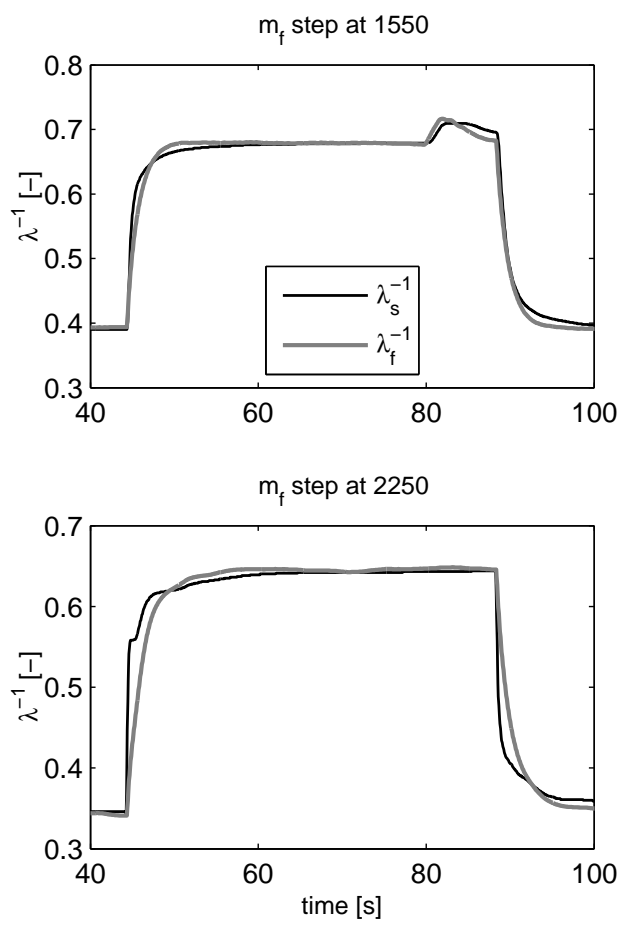

Figure 6: Example of identification of the sensor behaviour for two engine speeds, where $\lambda_{s}^{-1}$ and $\lambda_{f}^{-1}$ are depicted. Top plot: training data at $1550 \mathrm{rpm}$ where $\lambda_{f}^{-1}$ parameters $a$ and $\tau$ are identified. Bottom plot: validation data at $2250 \mathrm{rpm}$, where parameters $a$ and $\tau$ obtained for the top plot situation are used now for obtaining $\lambda_{f}^{-1}$.

\section{3. $\lambda^{-1}$ modelling}

Different $\lambda^{-1}$ models can be found in the literature, as those presented in [21, 22]. In this paper, a simple model is judged to be sufficient to track $\lambda^{-1}$ dynamic behaviour. Proposed model is the following 


$$
\lambda_{m}^{-1}=14.5 \frac{m_{f}}{m_{a}}
$$

where $m_{f}$ is the injected fuel mass as estimated by the ECU, $m_{a}$ is the air mass as measured using the series hot wire anemometer and 14.5 stands for the stoichiometric air-to-fuel ratio. Both $m_{f}$ and $m_{a}$ can be expressed as flows $(\mathrm{kg} / \mathrm{s})$ or in a cylinder and cycle basis (mg/stroke). The model neglects mass accumulation effects along intake and exhaust lines.

$\lambda_{m}^{-1}$ presents a significant bias that strongly depends on the operating conditions due to several facts:

- $m_{f}$ is obtained from internal calculations of the ECU, and response is fast and non-delayed, but is based on tabulated values which rely on rail pressure measurement and injection duration. The error of these tables can be significant when short injections or split injection strategies are applied. On the other hand, injector manufacturing discrepancies and ageing can create a significant unit-to-unit (and cylinder-to-cylinder [23, 24, 25]) dispersion in the actual injected quantity.

- While $m_{a}$ sensor response is judged to be fast and non-delayed enough for being directly used as a model input, the accuracy of the sensor is not very high (for example in [26] the non-systematic error of the air mass flow sensor was quantified with a standard deviation of $3.229 \%$, in part due to flow pulsations in the intake line associated with the engine speed). On the other hand, during transient processes in which significant variation of the air mass accumulated in the manifolds exist, the air mass flow measured in the intake line is different to that entering the engine [27]. This can be corrected accounting pressure variations in the $m_{a}$ estimation, although this is not considered in the current paper.

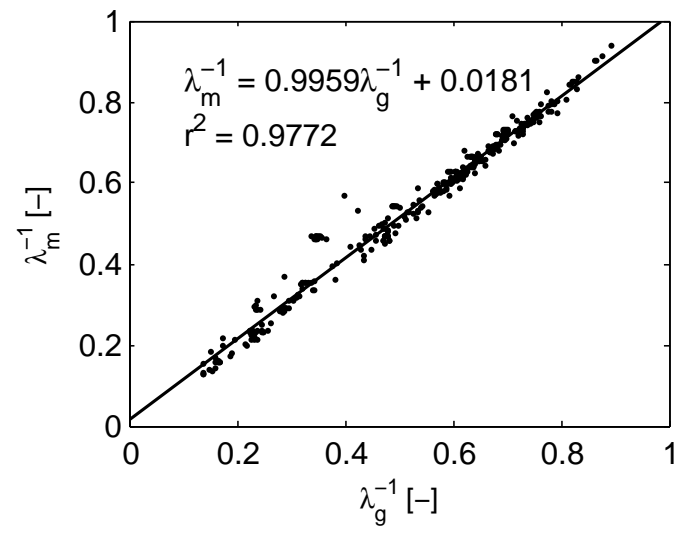

Figure 7: $\lambda_{m}^{-1}$ and $\lambda_{g}^{-1}$ for different steady operating conditions; linear fit and correlation coefficient is represented.

Figure 7 compares model steady-state results with gas analyser measurements. As it can be easily noticed, the model provides a lower accuracy than that of the sensor (shown in Figure 4). Regarding transient behaviour, model has a fast response as shown in Figure 3 for an injection step, although bias is clearly noticed. 
With this scenery, model output $\lambda_{m}^{-1}$ can be related to the actual value of $\lambda^{-1}$ considering a bias $\theta$

$$
\lambda_{m}^{-1}=\lambda^{-1}-\theta
$$

Model bias is not constant and varies with the operating condition, since $m_{a}$ error significantly depends on the engine speed, and $m_{f}$ error is affected by the injection profile (and hence torque). Figure 8 shows bias estimation for the measured steady points and its variation with engine speed and torque.
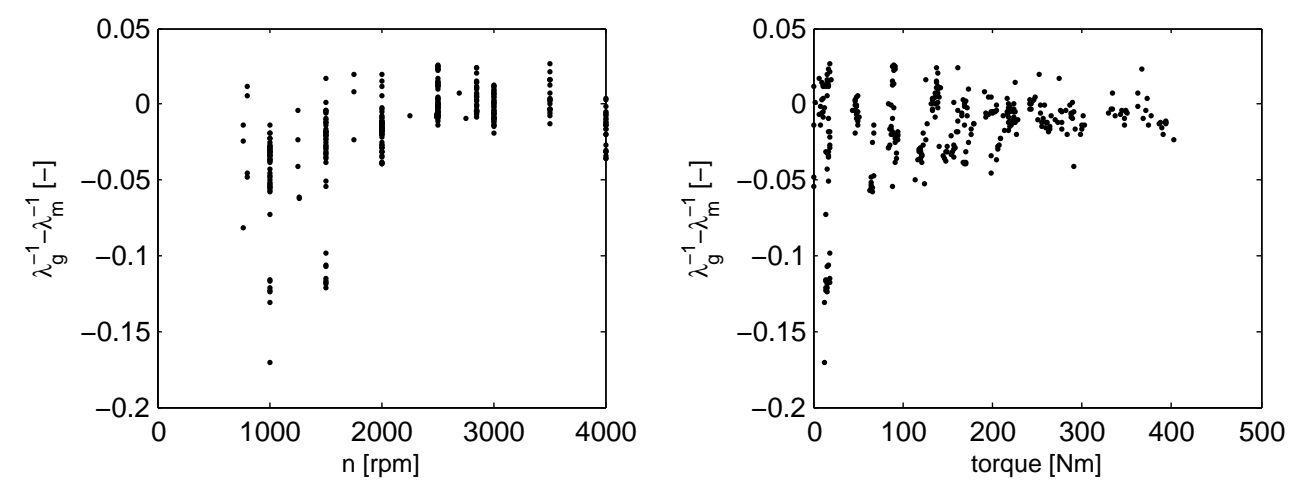

Figure 8: Model bias for the tests in Figure 7.

Additionally, bias varies with time due to the system drift, and a slow variation could be expected. Model drift may be associated with injection soiling, air mass flow sensor drift, or the variations of leakage in the intake manifold and blow-by. In order to model that, both effects, the dependency with the operative conditions, and the drift, must be considered

$$
\frac{\mathrm{d} \theta}{\mathrm{d} t}=\frac{\partial \theta}{\partial t}+\frac{\partial \theta}{\partial n} \frac{\mathrm{d} n}{\mathrm{~d} t}+\frac{\partial \theta}{\partial m_{f}} \frac{\mathrm{d} m_{f}}{\mathrm{~d} t}+\ldots
$$

Although the bias variation associated with the system drift $(\partial \theta / \partial t)$ is expected to be slow, the actual variation of the bias may be very fast, due to the ability of the engine of performing fast transition between operating conditions (defined by $n$ and $m_{f}$ ).

\section{Fast $\lambda^{-1}$ estimation}

\subsection{Problem set-up and methodology}

The goal is providing an estimation $\hat{\lambda}^{-1}$ of the actual value of $\lambda^{-1}$ combining the information provided by the sensor $\lambda_{s}^{-1}$ and the model $\lambda_{m}^{-1}$. Basic idea is keeping model dynamics while correcting model bias (and its drift) profiting the sensor steady performance.

Figure 9 summarises an schematic representation of the proposed structure. All calculations and equations are set-up in discrete form where $T$ represents the sampling period, which corresponds to $20 \mathrm{~ms}$ for the results shown in this paper. Main inputs are injected fuel mass $m_{f}$, air mass flow $m_{a}$, speed $n$ and sensor signal $\lambda_{s}^{-1}$. 
Because of the bias strong dependence with the operative conditions, a 2D look-up table $\Theta$ is used for accounting with this variation depending on engine speed and load. Hence current bias value may be represented as

$$
\theta_{k}=\Theta_{k}\left(n_{k}, m_{f, k}\right)+w_{k}
$$

where a noise $w$ is added to the tabulated value $\Theta_{k}\left(n_{k}, m_{f, k}\right)$ for considering modelling errors, and for dealing with the system drift.

Through the combination of the sensor and the model information (conveniently delayed for being comparable), a Kalman filter is used for tracking the value of the bias and of the filtered value of $\lambda^{-1}$, thus providing estimates $\hat{\theta}$ and $\hat{\lambda}_{f}^{-1}$. 'Freezing' conditions block adds robustness to the algorithm stopping the integration when sensor signals or model are not reliable.

In order to cope with the system drift, look-up table $\Theta$ is updated on a basis of an adaptive algorithm that uses the estimate $\hat{\theta}$

$$
\Theta_{k}=f\left(\Theta_{k-1}, \hat{\theta}_{k}\right)
$$

Finally, the estimation $\hat{\lambda}^{-1}$ is built up from the current model output $\lambda_{m}^{-1}$ and the tabulated value of the bias.

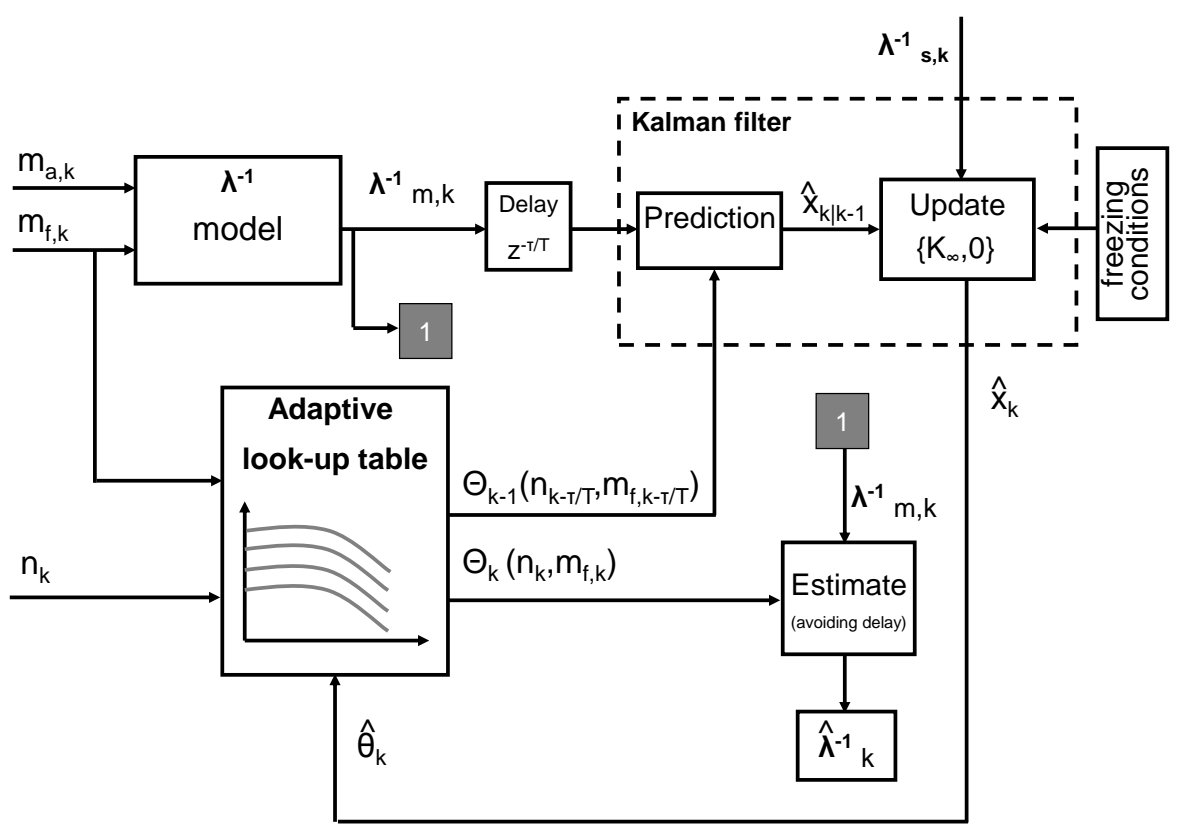

Figure 9: Schematic view of the proposed procedure for $\lambda^{-1}$ estimation.

\subsection{Observer design}

The proper combination of (2) and (1) allows to write the system in the following linear discrete time state space representation 


$$
\begin{aligned}
& x_{k}=A x_{k-1}+B u_{k}+W_{k} \\
& y_{k}=C x_{k}+v_{k}
\end{aligned}
$$

with the system state $x_{k}$, measurement $y_{k}$ and input $u_{k}$ defined as

$$
x_{k}=\left[\begin{array}{ll}
\theta & \lambda_{f}^{-1}
\end{array}\right]_{k}^{T} ; \quad y_{k}=\lambda_{s, k}^{-1} ; \quad u_{k}=\lambda_{m, k-\tau / T}^{-1}
$$

System (7) matrices are

$$
A=\left[\begin{array}{cc}
1 & 0 \\
1-a & a
\end{array}\right] ; B=\left[\begin{array}{c}
0 \\
1-a
\end{array}\right] ; W_{k}=\left[\begin{array}{c}
w_{k} \\
0
\end{array}\right] ; C=\left[\begin{array}{ll}
0 & 1
\end{array}\right]
$$

The optimal solution of the estimation problem (i.e. estimating the state $x$ of the system from the evolution of $y$ and $u$ ) was addressed by Kalman [11], and has been applied by different authors to the automotive domain (see for example $[9,10,28,29]$ ). In a first step, the state is estimated considering the system input and their expected dynamic characteristics

$$
\hat{x}_{k \mid k-1}=A \hat{x}_{k-1}+B u_{k}
$$

and in a second step the a priori estimate of the state $\hat{x}_{k \mid k-1}$ is updated using the error calculation $e_{k}$ and the Kalman filter gain $K_{k}$

$$
\begin{aligned}
& e_{k}=y_{k}-C \hat{x}_{k \mid k-1} \\
& \hat{x}_{k}=\hat{x}_{k \mid k-1}+K_{k} e_{k}
\end{aligned}
$$

Kalman gain $K_{k}$ is calculated recursively by solving the Ricatti equation which minimises the estimation error:

$$
\begin{aligned}
& P_{k \mid k-1}=A P_{k-1 \mid k-1} A^{\prime}+W \\
& K_{k}=P_{k \mid k-1} C^{\prime}\left(C P_{k \mid k-1} C^{\prime}+v\right)^{-1} \\
& P_{k \mid k}=\left(I-K_{k} C\right) P_{k \mid k-1}
\end{aligned}
$$

where $P$ matrix defines the estimation error variance. Since current application considers a linear time invariant (LTI) and a fully observable system, the filter is steady-state [30]. A constant Kalman gain matrix $K_{\infty}$ is then considered and calculated offline

$$
K_{\infty}=\lim _{k \rightarrow+\infty} K_{k}
$$

The use of a constant $K_{\infty}$ leads to a sub-optimal filter neglecting $K$ updating [31]. However, for the considered case this fact does not really matter because initial $P$ matrix is unknown and convergence is given after few iterations. Then the use of $K_{\infty}$ alleviates the computational burden and online implementation, thinking of its use in commercial ECUs. Anyway, if a more complex sensor model (including the effect of the operating conditions on the sensor dynamics) were employed, Kalman gain would vary with time, and then $K_{k}$ should be calculated online. 


\subsection{Observer tuning}

KF tuning consists on the adequate selection of noises $\sigma_{w}^{2}$ and $\sigma_{v}^{2}$ that affect process and sensor. Then, the optimal $K_{k}$ is calculated from these. Figure 10 shows the different values of the two elements of $K_{\infty}$ for different values of $\sigma_{w}^{2} / \sigma_{v}^{2}$. Bias gain is the first element of $K_{\infty}$ vector and sensor model gain is the last element of $K_{\infty}$ vector. Note that the lower the sensor noise is considered (higher $\sigma_{w}^{2} / \sigma_{v}^{2}$ ), the faster the states' estimations are updated (because sensor measurement is propagated to the states).

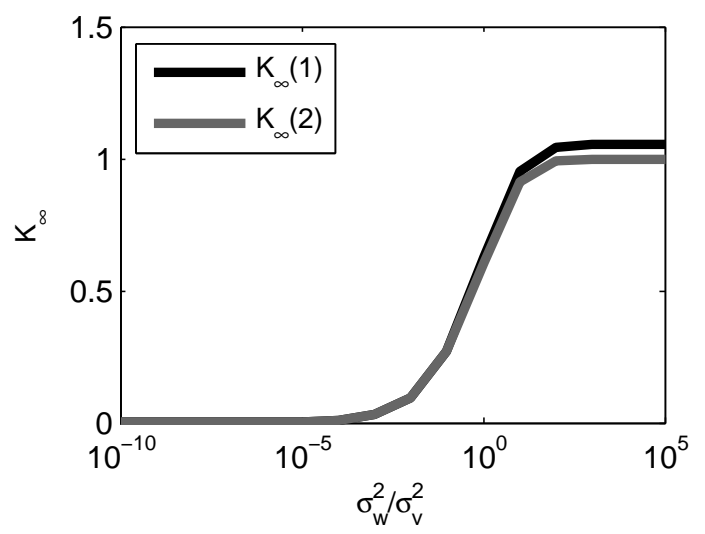

Figure 10: Evolution of elements $K_{\infty}$ gain vector when varying $\sigma_{w}^{2} / \sigma_{v}^{2}$.

Hence, the gain selection defines how fast the bias is cancelled, but two issues must be considered:

- The filter also rejects the sensor noise. Using a very high Kalman gain implies do not filtering the measurement noise.

- If the sensor dynamics characteristics are not perfectly known, a high value of the gain causes the system to rely on incorrect information, and then peaks appear in the $\hat{\lambda}^{-1}$.

For illustrating the latter issue, synthetic signals of a first order model as (1) are used. A step transition in $\lambda^{-1}$ is simulated, but using $a^{\prime}=a \pm \sigma_{a}, \tau^{\prime}= \pm \sigma_{\tau}$, and initial and final values of bias $\theta_{0}, \theta_{1}$. Since synthetic signals are used, filter performance can be evaluated through the comparison of $\hat{\lambda}^{-1}$ with actual $\lambda^{-1}$. Results can be seen in Figure 11. Basic cases correspond to:

1. Sensor perfectly known $\left(a^{\prime}=a, \tau^{\prime}=\tau\right)$ with an step in the bias $\left(\theta_{0} \neq \theta_{1}\right)$. In this case, the higher $K_{\infty}$ is, the faster the bias is corrected, as depicted in the top plot of Figure 11.

2. Constant bias and uncertainty on the sensor description $\left(a^{\prime} \neq a, \tau^{\prime} \neq \tau\right)$. In this case high $K_{\infty}$ values yield to rely excessively on the poorly known sensor dynamics, creating artificial peaks, as shown in bottom plot of Figure 11.

The general error case in the sensor modelling is a (non-linear) superposition of the previous cases, and it is clear that a trade-off in the selection of the $K_{\infty}$ must be considered according to the signals uncertainties and the required convergence speed. For the considered application, sensor exhibits a significant variation in their dynamic properties and a consistent model has not 

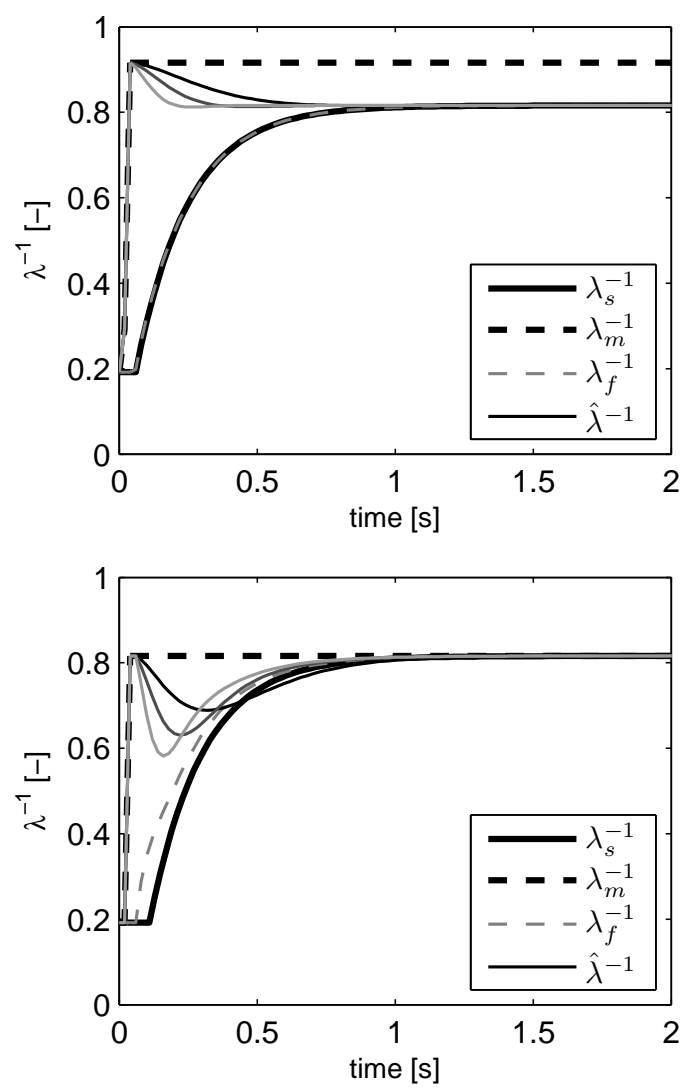

Figure 11: $\hat{\lambda}^{-1}$ simulation using Kalman filter with three different kalman gain values, where from lighter to darker lines corresponds from higher to lower kalman gain values. Top plot is for the case of sensor model perfectly known $\left(a^{\prime}=a, \tau^{\prime}=\tau\right)$ with an step in $\theta$, meanwhile bottom plot corresponds to the case of $\left(a^{\prime} \neq a, \tau^{\prime} \neq \tau\right)$ with constant $\theta$.

been derived for the whole engine operating range. This would force a low value of $K_{\infty}$ (and hence a slow correction of the model bias), but several modifications are proposed next.

Data based methods could be used for estimating the appropriate noise trade-off [32]. Here, filter tuning is made by the Monte Carlo based method application presented in [33], where sensor knowledge uncertainties, expected working points ( $n$ and $m_{f}$ values) and different expected $\theta$ are used for evaluating the filter performance under different $\sigma_{w}^{2} / \sigma_{v}^{2}$ values. These variations are considered with statistical distributions, and the configuration which minimises the total error is selected.

\subsection{Robustness against signals uncertainties}

Three main circumstances affect the correct algorithm performance:

- Sensor saturation: $\mathrm{NO}_{\mathrm{x}}$ sensors exhibit saturation problems for high $\mathrm{O}_{2}$ partial pressures (low $\lambda^{-1}$ ). Figure 12 shows clearly the saturation point for the tested $\mathrm{NO}_{\mathrm{x}}$ sensor, where two units of this model are located downstream the turbo and downstream the after-treatment 
systems. If KF is active, integration would be incorrect in these situations as far as $\lambda_{s}^{-1}$ is not reliable.

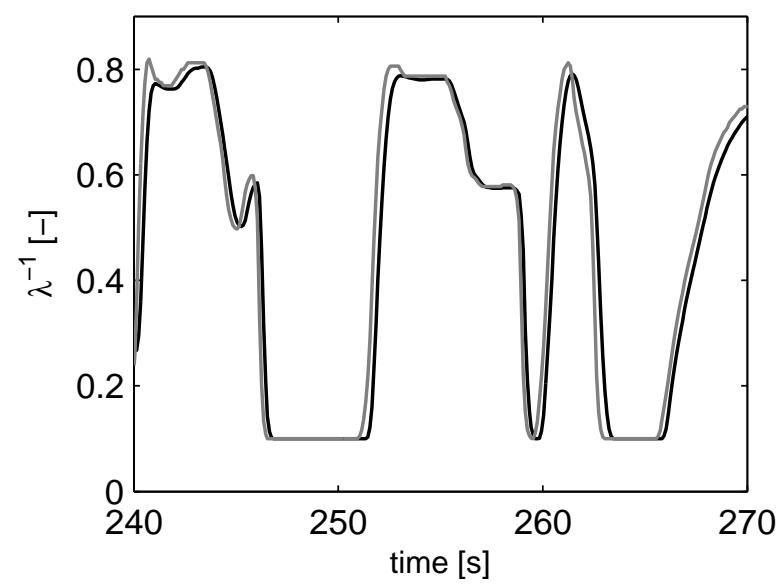

Figure 12: $\lambda^{-1}$ measurement from a $\mathrm{NO}_{\mathrm{x}}$ sensor located downstream the turbine (gray) and a $\mathrm{NO}_{\mathrm{x}}$ sensor located downstream the after-treatment systems (black). Both sensors are the same commercial model and present a saturation in approximately $\lambda^{-1}=0.1$.

- Sensor and model uncertainties during highly dynamic transients: Sensor behaviour, defined by $a$ and $\tau$, varies with time, boundary conditions, system conditions and because of ageing and unit-to-unit dispersion. For avoiding wrong integrations, this must be considered. Furthermore, sensor model considered in (1) could not be complex enough for accounting with actual sensor performance. An incorrect sensor model leads to peak errors, especially when a sharp transient occurs.

- Spurious measurements: Signals involved can present outliers or errors that could be fatal for the algorithm.

When these occur, integration must stop. A set of deactivation IF-THEN or 'freezing' rules have been programmed for that. If some of the following conditions is true, then $e_{k}=0$ :

$$
\begin{aligned}
e_{k} \frac{1-z^{-1}}{T} & >F_{1} \\
\lambda_{m}^{-1} \frac{1-z^{-1}}{T} & >F_{2} \\
\lambda_{s}^{-1} \frac{1-z^{-1}}{T} & >F_{3} \\
\lambda_{s}^{-1} & <F_{4} \\
\lambda_{s}^{-1} & >F_{5} \\
\hat{\lambda}^{-1} & <F_{6} \\
\hat{\lambda}^{-1} & >F_{7}
\end{aligned}
$$


where (14a) to (14c) deactivate the filter in highly dynamic transients or in the case of spurious measurements; (14d) if sensor saturation occurs; (14e) if measurement outliers are detected; finally (14f) and (14g) are included for providing robustness to the estimation. These conditions make the table update highly insensitive to sensor model errors, sensor output errors and model output errors.

Setting this kind of rule allows using a much higher Kalman gain because the integration during areas where $\theta$ is not correctly estimated is avoided. The definition of the rules and thresholds needs to be done accordingly with the level of uncertainty in the sensor knowledge, the signals noise level, model reliability and assumptions concerning the dynamic characteristics of the $\lambda^{-1}$ evolution.

Figure 14 already showed $\hat{\lambda}^{-1}$ in injection steps when using the freezing rules. Figure 13 compares $\hat{\lambda}^{-1}$ obtained with two different freezing conditions for one sharp injection transient, where $\lambda^{-1}$ value is drastically varied and the bias is affected by the operating conditions (it varies from 0 at the beginning of the test to 0.1 after the fuel step). In all cases, a significant error in the sensor model is assumed $\left(a^{\prime} \neq a\right.$ and $\left.\tau^{\prime} \neq \tau\right)$. It can be also noticed that including freezing mitigates the overshoot in the correction; although an excessive freezing will result to completely deactivating the integration of the filter, and then no bias correction would be made during engine operation. Monte Carlo calibration method presented in [33] can also be used for tuning freezing thresholds $F_{1}$ to $F_{7}$.

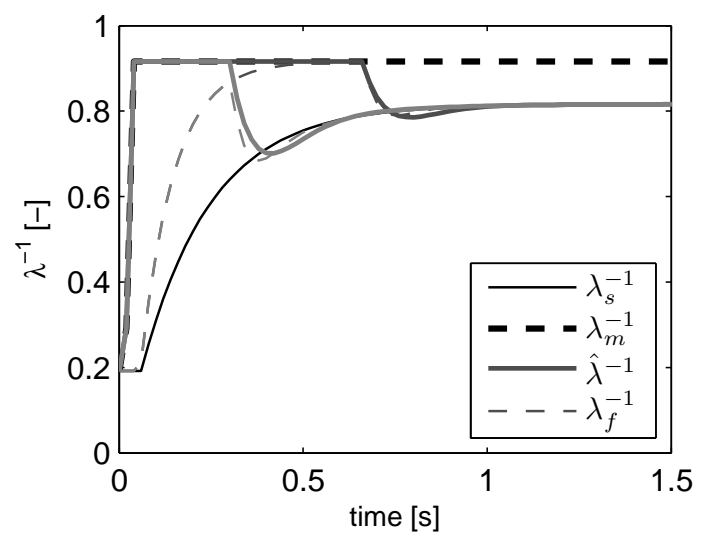

Figure 13: $\hat{\lambda}^{-1}$ for two different conditions of freezing for an injection step at $2250 \mathrm{rpm}$. Thin solid lines represents $\hat{\lambda}^{-1}$, lighter to darker gray is less to more severe freezing condition. $\lambda_{f}^{-1}$ models for each $\hat{\lambda}^{-1}$ are also included.

\subsection{Look-up table adaptation and $\lambda^{-1}$ estimation}

Look-up table in Figure 9 is used for coping with the bias dependence with the operative conditions. The look-up table interpolation principle is based on a $2 \mathrm{D}$ bilinear interpolation considering the 4 neighbours. If some point is beyond the defined table scheduling points, the value is saturated to the closest one for avoiding incorrect calculations. At every iteration, the initial estimation of the bias is interpolated from the table $\Theta$

$$
\hat{\theta}_{k \mid k-1}=\Theta_{k-1}\left(n_{k-\tau / T}, m_{f, k-\tau / T}\right)
$$


where table scheduling inputs engine speed $n$ and injected fuel mass $m_{f}$ are conveniently delayed in order to consider the sensor delay. The Kalman filter provides an updated value of the bias (at the delayed input conditions) that is used for updating the table with a learning method. There are several possibilities for the table adaptation in the literature [34, 35, 36]; here the method explained in [37], a KF-based algorithm for updating look-up tables, is used. While considering the table as an independent block, the system keeps simple. At every iteration, only the equation (11b) must be solved as far as $K_{k}$ has been precalculated offline. The main benefit of this is that the converged $K_{\infty}$ obtained for the filter remains constant although the table changes its elements, without affecting the calculation burden.

Once the table has been adapted, an updated value of the bias is obtained for the current operative conditions, which is used for building the final estimation:

$$
\hat{\lambda}_{k}^{-1}=\lambda_{m, k}^{-1}+\Theta_{k}\left(n_{k}, m_{f, k}\right)
$$

where current values of the inputs and the model are used, in order to provide the more updated information. 

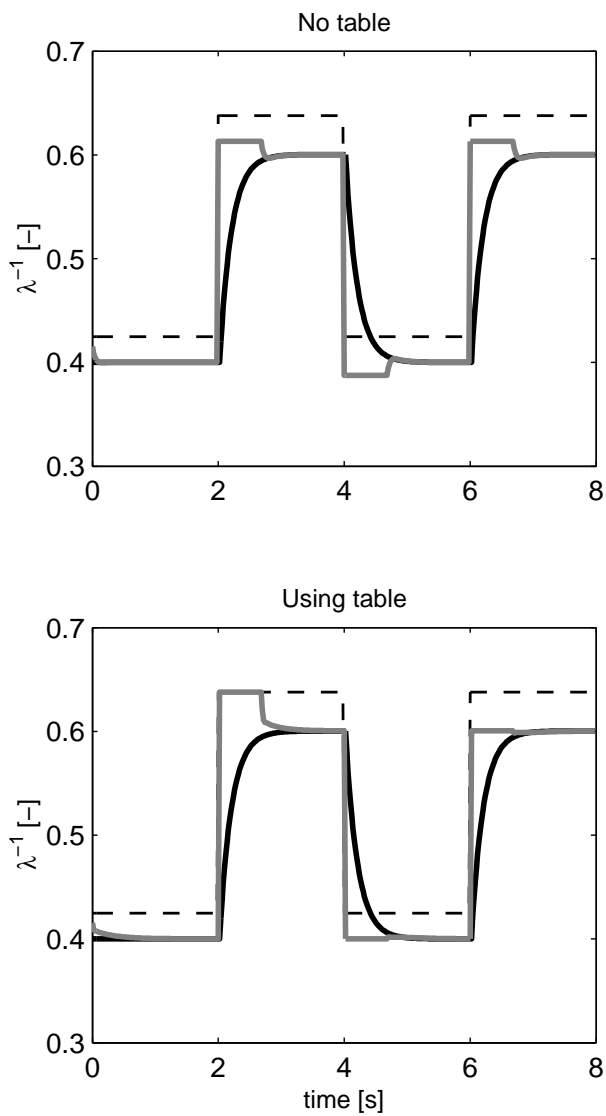

Figure 14: $\hat{\lambda}^{-1}$ without table (top) and using adaptive table (bottom) changing the operating point condition of the engine repeating two times a cycle using simulation data. Black line is $\lambda_{s}^{-1}$, dashed black line is $\lambda_{m}^{-1}$ and gray line is $\hat{\lambda}^{-1}$. Deactivation freezing rules are applied.

For illustrating the look-up table performance, Figure 14 shows the simulation of $\lambda^{-1}$ for a repetition of the same profile. $\tau$ is known and null and $a$ has a certain error. Top plot represents the evolution if the adaptive table is not used. In the case of using the adaptive table (bottom plot), first part of the cycle serves for bias identification (initially all elements of the table are set to zero), and in the second part of the cycle the estimation is significantly improved because of the stored values. Note that during transients integration, error integration starts slightly after the step because of deactivation freezing rules.

Different tables may also be used in case of using different combustion modes (split injection, exhaust system regeneration) or coolant temperature, in order to cope with the different bias in the $m_{f}$ estimate when the injection settings change. Each table is updated only when the mode is activated and can add more accuracy to the estimate although incrementing the programming burden. 


\section{Experimental validation}

This section covers the experimental validation of the algorithm.In order to provide a reference signal for assessing the algorithm, injection steps are performed in the engine and $\hat{\lambda}^{-1}$ calculated. Since injection is a fast acting control variable, actual $\lambda^{-1}$ response is judged to be instantaneous and no more than one engine cycle delay is expected, being able to generate a reference for comparison. Furthermore, this signal is available online, making that algorithm may be tuned and proved without an specific test rig beyond the engine and ECU itself.

Layout is the same of section 2, sensor model parameters are identified beforehand as in section 2.2 with values $a=0.96$ and $\tau=0.4 s . K_{\infty}$ is precalculated offline for all cases as Kalman filter is steady-state. Sample frequency is $50 \mathrm{~Hz}$. Figure 15 shows the results for a set of different injection steps for a constant engine speed $n=1500 \mathrm{rpm} . \mathrm{ZrO}_{2}$ sensor is located downstream the after-treatment systems and a significant bias 0.05 times its own value has been added for exaggerating the correction; i.e $\lambda_{m, \text { drifted }}^{-1}=1.05 \times \lambda_{m}^{-1}$. Furthermore, $\lambda_{m}^{-1}$ presents a significant variable bias depending on the operating point with respect to $\lambda_{s}^{-1}$. Drift correction algorithm is employed for estimating $\lambda^{-1}$. Freezing conditions are relaxed because sensor model is wellknown. Top plot shows an example with low correction where integration is quite slow. Bottom plot shows the opposite situation where integration is quite fast, provoking some peaks but getting before the steady-state value of the sensor. Here, no model or table is used for bias. This makes that after every step, bias must be integrated for coping with its variation. 

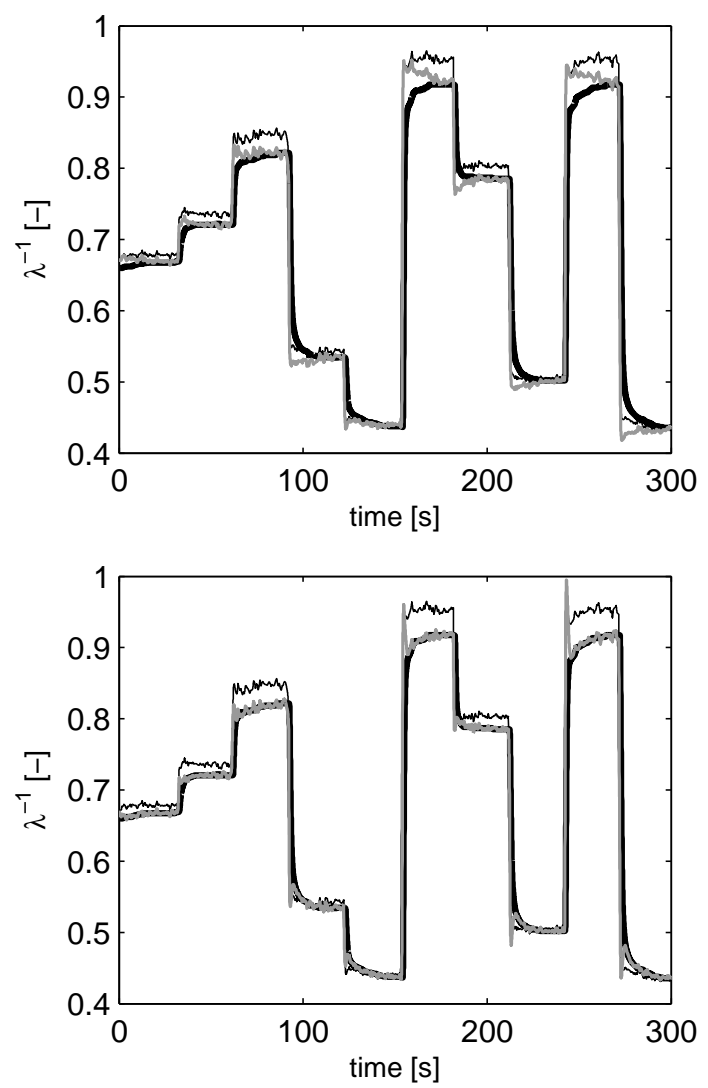

Figure 15: $\hat{\lambda}^{-1}$ performing injection steps at $1500 \mathrm{rpm}$ without using look-up table. Top plot: Slow correction, with $\sigma_{w}^{2} / \sigma_{v}^{2}=1 / 80$. Bottom plot: Fast correction, with $\sigma_{w}^{2} / \sigma_{v}^{2}=1 / 30$. Legend: Thick black is $\lambda_{s}^{-1}$, thin black is $\lambda_{m}^{-1}$ and gray is $\hat{\lambda}^{-1}$.

Bias is modelled using an adaptive look-up table (16) depending on the operating point conditions. This smoothes bias integration when operating point changes once that table has been learnt. Then, Figure 16 shows same situation of Figure 15 but now using a look-up table. Table grid has a density for $n$ of one point every $500 \mathrm{rpm}$ between 500 and $5000 \mathrm{rpm}$ and for $m_{f}$ of one point every $1 \mathrm{mg} / \mathrm{str}$. 


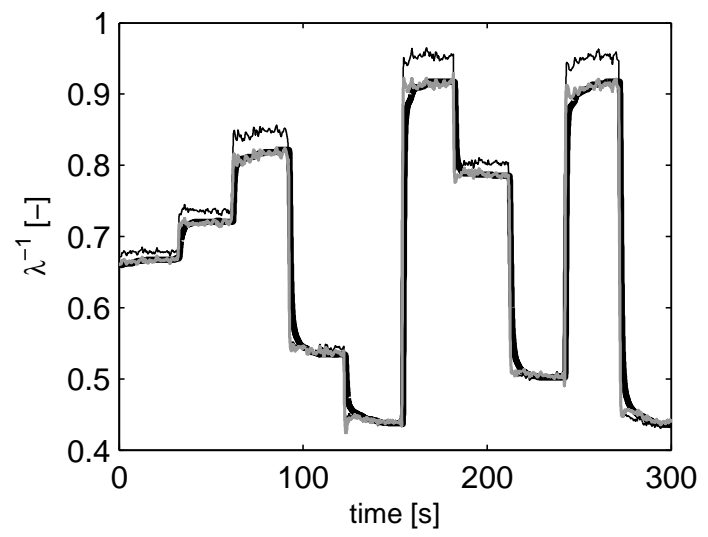

Figure 16: $\hat{\lambda}^{-1}$ performing injection steps at $1500 \mathrm{rpm}$ using look-up table. Legend: Thick black is $\lambda_{s}^{-1}$, thin black is $\lambda_{m}^{-1}$ and gray is $\hat{\lambda}^{-1}$. Values for Kalman filter tuning are $\sigma_{w}^{2} / \sigma_{v}^{2}=1 / 80$.

Figure 17 shows final results for three different injection steps of the previous cycle once that bias has been perfectly learnt and for the actual $\lambda_{m}^{-1}$ (no extra bias is added). $\hat{\lambda}^{-1}$ keeps fast dynamics but converges to the steady-state value of $\lambda_{m}^{-1}$, in contrast to the biased model and the slow sensor. 

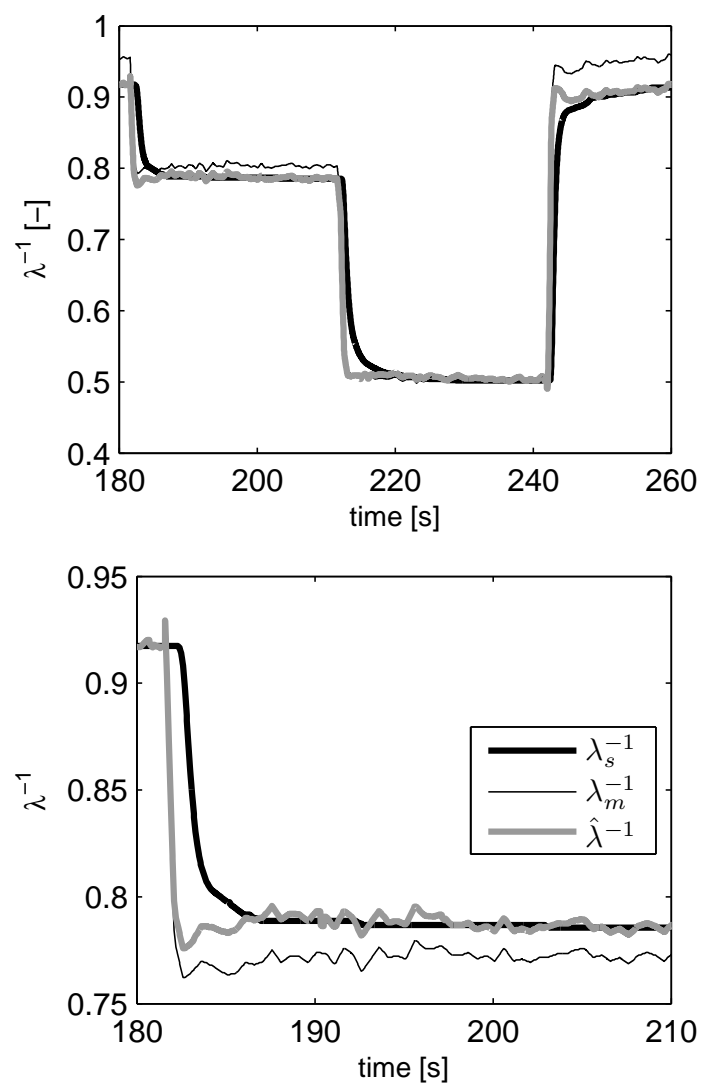

Figure 17: $\hat{\lambda}-1$ using table and freezing conditions performing injection steps at $1500 \mathrm{rpm}$. Top picture presents three injection steps, while bottom one shows a zoom in the first injection step.

Finally, algorithm is proven with the NEDC and shown in Figure 18 for a window of the cycle. Described conditions and data for previous tests are still valid here. $\hat{\lambda}^{-1}$ keeps model dynamics but evolves correcting the drift relying on the steady-state value of the sensor. This test is representative of real driving conditions and procedure demonstrates its feasibility for being used in commercial vehicles. 


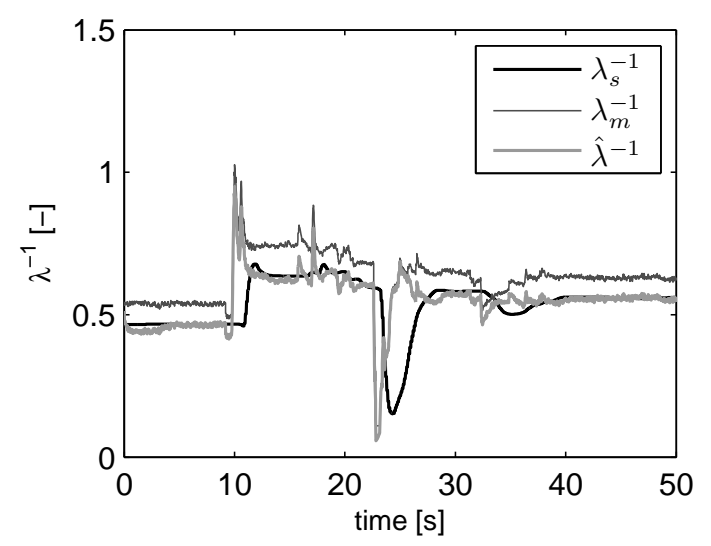

Figure 18: $\hat{\lambda}^{-1}$ using table and freezing conditions in NEDC cycle.

\section{Conclusions}

$\lambda^{-1}$ fast estimation in a turbocharged diesel engine is addressed. For that, two different information sources are used: a fast model based on the fuel-to-air ratio calculation, whose dynamic performance is good but suffers from bias; and a slow $\mathrm{NO}_{\mathrm{x}}$ sensor that provides $\lambda^{-1}$ with deficient dynamic response but good steady-state accuracy. Model and sensor are combined building a bias model by means of a LTI linear state space model. State estimation is done by means of a Kalman filter. Three main modifications are done to the classical KF solution:

1. In order to cope with sensor uncertainties (because the sensor behaviour is non-linear and depends on the operating conditions, and it is also affected by ageing and manufacturing discrepancies) some deactivating conditions, referred in this paper as freezing conditions, are used. These rules literally freeze the integration of the Kalman filter, rejecting the bias integration in the cases some signal information is not trustful.

2. Bias is modelled by means of using an adaptive look-up table for coping with operating point dependence. Table output acts as a prepositioning input for the Kalman filter, avoiding integration work, and improving the estimate. Table parameters are identified with a KFbased method.

3. In order to alleviate the computational cost, and because of the system is time-invariant, the steady-state Kalman gain is computed beforehand.

The system is tested on a turbocharged diesel engine with good results, obtaining a reliable and fast $\hat{\lambda}^{-1}$ estimation. Although the algorithm is directly applied to the $\lambda^{-1}$ estimation with a certain model, this can be easily applied to other variables with similar characteristics, such as $\mathrm{NO}_{\mathrm{x}}$ estimation and other models.

\section{Acknowledgement}

This work has been partially financed through project HIREFIRE. 


\section{Bibliography}

[1] H. Dueker, K. H. Friese, and W. D. Haecker, “Ceramic aspects of the bosch lambda-sensor," SAE paper 750223, 1975.

[2] X. Lu, D. Han, and Z. Huang, "Fuel design and management for the control of advanced compression-ignition combustion modes," Progress in Energy and Combustion Science, vol. 37, pp. 741-783, 2011.

[3] C. J. Chiang, A. G. Stefanopoulou, and M. Jankovic, "Transitions in homogeneous charge compression ignition engines," IEEE Transactions on Control Systems Technology, vol. 15, no. 3, pp. 438 - 448, 2007.

[4] F. Agrell, H. E. Angström, B. Eriksson, J. Wikander, and J. Linderyd, "Transient control of HCCI combustion by aid of variable valve timing through the use of a engine state corrected CA50-controller combined with an in-cylinder state estimator estimating lambda," SAE paper 2005-01-2128, 2005.

[5] N. Kato, K. Nakagaki, and N. Ina, “Thick film $\mathrm{ZrO}_{2} \mathrm{NO}_{\mathrm{x}}$ sensor," SAE paper 960334, 1996.

[6] J. Riegel, H. Neumann, and H. M. Wiedenmann, "Exhaust gas sensors for automotive emission control," Solid State Ionics, vol. 152-153, pp. 783-800, 2002.

[7] S. Zhuiykov and N. Miura, "Development of zirconia-based potentiometric $\mathrm{NO}_{\mathrm{x}}$ sensors for automotive and energy industries in the early 21st century: What are the prospects for sensors?" Sensors and Actuators B 121, p. 639651, 2007.

[8] 2007 Regulation (EC) No 715/2007 of the European Parliament and of the Council of 20 June 2007 on type approval of motor vehicles with respect to emissions from light passenger and commercial vehicles (Euro 5 and Euro 6) and on access to vehicle repair and maintenance information. Official Journal of the European Union, 2007. [Online]. Available: http://eur-lex.europa.eu/LexUriServ/LexUriServ.do?uri=CELEX:32007R0715:EN:NOT

[9] A. Schilling, A. Amstutz, and L. Guzzella, "Model-based detection and isolation of faults due to ageing in the air and fuel paths of common-rail direct injection diesel engines equipped with a $\lambda$ and a nitrogen oxides sensor," Proceedings of the Institution of Mechanical Engineers, Part D: Journal of Automobile Engineering, vol. 222, pp. 101-117, 2008.

[10] D. Alberer and L. del Re, "Fast oxygen based transient diesel engine operation," SAE paper 2009-01-0622, 2009.

[11] R. E. Kalman, "A new approach to linear filtering and prediction problems," Journal of Basic Engineering, vol. 82 no. 35-45, 1960 .

[12] V. K. Jones, B. A. Ault, G. F. Franklin, and J. D. Powell, "Identification and air-fuel ratio control of a spark-ignition engine," IEEE Transactions on Control Systems Technology, vol. 3, no. 1, pp. 14 - 21, 1995.

[13] C. F. Chang, N. P. Fekete, A. Amstutz, and J. D. Powell, "Air-fuel ratio control in spark-ignition engines using estimation theory," IEEE Transactions on Control Systems Technology, vol. 3, no. 1, pp. 22 - 31, 1995.

[14] J. R. Wagner, D. M. Dawson, and Z. Liu, "Nonlinear air-to-fuel ratio and engine speed control for hybrid vehicles," IEEE Transactions on Vehicular Technology, vol. 52, no. 1, pp. 184 - 195, 2003.

[15] K. R. Muske, J. C. P. Jones, and E. M. Franceschi, "Adaptive analytical model-based control for si engine airfuel ratio," IEEE Transactions on Control Systems Technology, vol. 16, no. 4, pp. 763 - 768, 2008

[16] J. Galindo, J. M. Luján, H. Climent, and C. Guardiola, "Turbocharging system design of a sequentially turbocharged diesel engine by means of a wave action model," SAE paper 2007-01-1564, 2007.

[17] K. Ogata, Modern Control Engineering (4th Edition). Prentice Hall, 2001.

[18] S. Regitz and N. Collings, "Fast response air-to-fuel ratio measurements using a novel device based on a wide band lambda sensor," Meas. Sci and Technol., vol. 19, no. 075201, 2008.

[19] J. Galindo, J. R. Serrano, C. Guardiola, D. Blanco-Rodriguez, and I. G. Cuadrado, "An on-engine method for dynamic characterisation of $\mathrm{NO}_{\mathrm{x}}$ concentration sensors," Experimental Thermal and Fluid Science, vol. 35, p. 470476, 2011.

[20] L. Ljung, "Asymptotic behavior of the extended Kalman filter as a parameter estimator for linear systems," IEEE Transactions on Automatic Control, vol. 24, pp. 36-50, 1979.

[21] M. Nyberg and T. Stutte, "Model based diagnosis of the air path of an automotive diesel engine," Control Engineering Practice, vol. 12, pp. 513-525, 2004.

[22] N. Cesario, M. D. Meglio, F. Pirozzi, G. Moselli, F. Taglialatela, and F. Carpentieri, "Air/fuel control system in SI engines based on virtual lambda sensor," SAE paper 2005-24-058, 2005.

[23] V. Macian, J. M. Luján, C. Guardiola, and P. Yuste, "DFT-based controller for fuel injection unevenness correction in turbocharged diesel engines," IEEE Transactions on Control Systems Technology, vol. 14, no. 5, pp. 819 - 827, 2006.

[24] V. Macian, J. M. Luján, C. Guardiola, and A. Perles, "A comparison of different methods for fuel delivery unevenness detection in diesel engines," Mechanical Systems and Signal Processing, vol. 20, no. 8, pp. 2219-2231, 2006.

[25] F. Payri, J. M. Luján, C. Guardiola, and G. Rizzoni, "Injection diagnosis through common-rail pressure measurement," Proc. Inst. Mech. Eng., Part D: Journal of Automobile Engineering, vol. 220, no. 3, pp. 347-357, 2006. 
[26] J. M. Desantes, J. Galindo, C. Guardiola, and V. Dolz, "Air mass flow estimation in turbocharged diesel engines from in-cylinder pressure measurement," Experimental Thermal and Fluid Science, vol. 34 (1), pp. 37-47, 2010.

[27] J. Galindo, H. Climent, C. Guardiola, and J. Doménech, "Strategies for improving the mode transition in a sequential parallel turbocharged automotive diesel engine," International Journal of Automotive Technology, vol. 10 (2), pp. 141-149, 2009

[28] A. Schilling, A. Amstutz, C. H. Onder, and L. Guzzella, "A real-time model for the prediction of the $\mathrm{NO}_{\mathrm{x}}$ emissions in DI diesel engines," in Proceedings of the 2006 IEEE International Conference on Control Applications, Munich, Germany, October 4-6, 2006.

[29] J. M. Desantes, J. M. Luján, C. Guardiola, and D. Blanco-Rodriguez, "Development of $\mathrm{NO}_{\mathrm{x}}$ fast estimate using $\mathrm{NO}_{\mathrm{x}}$ sensors," in EAEC 2011 Congress, Valencia, 2011

[30] R. E. Kalman and R. S. Bucy, "New results in linear filtering and prediction theory," Journal of Basic Engineering, pp. 95-108, March 1961.

[31] D. Simon, "Kalman filtering," Embedded Systems Programming, vol. 14, no. 6, pp. 72-79, 2001.

[32] M. R. Rajamani and J. B. Rawlings, "Estimation of the disturbance structure from data using semidefinite programming and optimal weighting," Automatica, vol. 45, pp. 142-148, 2009.

[33] F. Payri, C. Guardiola, D. Blanco-Rodriguez, A. Mazer, and A. Cornette, "Methodology for design and calibration of a drift compensation method for fuel-to-air ratio estimation," SAE paper 2012-01-0717, 2012.

[34] E. Höckerdal, E. Frisk, and L. Eriksson, "EKF-based adaptation of look-up tables with an air mass-flow sensor application," Control Engineering Practice, vol. 19, pp. 442-453, 2011.

[35] G. Wu, "A table update method for adaptive knock control," SAE paper 2006-01-0607, 2006.

[36] J. C. Peyton Jones and K. R. Muske, "Identification and adaptation of linear look-up table parameters using an efficient recursive least-squares technique," ISA Transactions, vol. 48, no. 4, pp. 476 - 483, 2009.

[37] C. Guardiola, B. Pla, D. Blanco-Rodriguez, and P. Cabrera, "A learning algorithm concept for updating look-up tables for automotive applications," Mathematical and Computer Modelling, 2012. 